УДК 291.11.

ББК 86.2

DOI 10.31554/2222-9175-2019-33-218-224

Р. А. Зобков

МЕТАФИЗИЧЕСКАЯ, ОНТОАОГИЧЕСКАЯ

И ГНОСЕОАОГИЧЕСКАЯ СТРУКТУРА

УНИВЕРСАИИЗМА РЕНЕ ГЕНОНА

В статье рассматриваются проблемы сконструированного Рене Геноном интегрального традиционализма как метафизического, онтологического и гносеологического комплекса, который становится в его философии методологической системой критики европейского универсализма с позиции аксиоматики премодерна. Основным пунктом этой критики является расхождение понятий метафизики и онтологии, лежащих, по Р. Генону, в основании проблем западной цивилизации.

Ключевые слова: интегральный традиционализм, Рене Генон, метафизика, онтология, гносеология, универсализм.

R. A. Zobkov

\title{
METAPHYSICAL, ONTOLOGICAL AND GNOSEOLOGICAL STRUCTURE OF RENÉ GUÉNON'S UNIVERSALISM
}

The article deals with the problems of René Guénon's integral traditionalism as a metaphysical, ontological and epistemological complex, which becomes a methodological system of criticism of European universalism from the position of axiomatics of premodern in the philosophy of the author. The problems of discrepancy between the concepts of metaphysics and ontology as the main problem of Western civilization are touched upon.

Keywords: Integral Traditionalism, René Guénon, metaphysics, ontology, epistemology, universalism.

$\mathrm{Y}$ чение интегрального традиционализма возникло в начале XX в., оно было сформулировано Рене Геноном, а также Юлиусом Эволой, Анандой Кумаросвами и др. Традиционализм как некая идеологическая доктрина возникает как критика современного мира, это ответ модерну языком модерна со стороны традиции, в котором методология и средства деконструкции, с помощью которых модерн разрушал и критиковал традицию, направляются уже на него самого. Появление традиционализма связано с антиметафизической направленностью западной философии, выразившейся в материализме и позитивизме, и традиционализм - это закономерный ответ представителей метафизики на попытки ее деконструкции со стороны позитивистов, прагматиков и утилитаристов.

Философия интегрального традиционализма Рене Генона оказала значительное влияние на гуманитарную науку XX в., и в последнее время интерес к ней вновь выpoc: все большее число религиозных, политических и парарелигиозных движений

ЗОБКОВ Роман Александрович - аспирант Федерального государственного бюджетного учреждения науки «Институт монголоведения, буддологии и тибетологии СО РАН» (Улан-Удэ, Россия). E-mail: zobkovroman@ yandex.ru. 
(в т. ч. и в России) осмысляют современность через призму идей Генона. «Генонизм» в настоящее время становится заметным фактором влияния на культурные, политические, философские тенденции.

Исследованием интегрального традиционализма в различных его аспектах занимались как зарубежные исследователи - Рене Алло, М. Скрябин [Alleau, Scriabine 1981], Джордж Валлин [Vallin 1959], Вилльям Кенеди [Kennedy 1994-2008], Марк Сэджвик [2014], так и отечественные - Александр Дугин [2002], Юрий Стефанов [1994], Владимир Карпец [Электронный ресурс], но трактовка метафизикой онтологической и гносеологической проблематики в творчестве Рене Генона как антитезы западноевропейскому философствованию нового времени не становилась предметом специального исследования.

Задачами данной статьи является выявление структуры философствования основателя интегрального традиционализма Рене Генона, определение степени его радикальности и новизны по отношению к традиции западноевропейской философской мысли, выявление пунктов критики Рене Геноном западноевропейской цивилизации.

Рассмотрим, прежде всего, что является метафизикой для самого Рене Генона. Термин «метафизика» в том значении, который он использует, не соотносится с историко-философской традицией западноевропейской философии, это подчеркивает сам Р. Генон [2013: 96]. Метафизика для Р. Генона - это знание принципов, принадлежащих универсальному порядку, это принцип максимального обобщения и максимального абстрагирования, из которого и проистекают основные принципы более низкого порядка, сам же первопринцип не может быть определен в силу имманентно присущей ему безграничности, и любое его определение подразумевало бы его ограничение. По сути, подлинный метафизический принцип находится за пределами его определения [2008: 55; 2012: 30; 2013: 97]. Этот метафизический принцип включает в себя все частные предметы и науки, но сам предмет метафизики не может быть чем-то, он не может сравниваться ни с одной частной областью, не может изменяться под действием времени и пространства [2013: 35-99]. Метафизический принцип преодолевает любые пары противоположностей, такие как дух и материя, сущность и субстанция, целое и часть, общее и индивидуальное, любые идеи чистого сущего во всей его универсальности. Метафизика не может быть ограничена ничем [Там же: 135]. Метафизика Генона не совпадает с онтологией, так как онтология - это учение о бытии и сущем, а они есть лишь частные принципы более низкого порядка по отношению к универсальному метафизическому принципу [2004: гл. I; 2013: 136]. Подлинная метафизическая область находится за гранью бытия [2012: 25]. Метафизическая область не подлежит никакой систематизации по определению, поскольку любой вид систематики будет ее ограничивать. Также он утверждает, что метафизика не является ни философией, ни религией. Абсолют Р. Генона - это предельный метафизический принцип, который выводится из закона «отрицания отрицания». Любое определение предполагает ограничение, ограничение - это отрицание, устанавливающее границу того, что лежит за пределами определяемого, отрицание чего-то, что не входит в определяемое. Если определяемое поистине безгранично, оно выводится через отрицание любого отрицания, и принцип «отрицания отрицания» в итоге дает максимальное, тотальное и абсолютное утверждение [Там же: 29]. Таким образом, метафизика - идея бесконечного, самая утвердительная и универсальная, заключает в себе все остальные частные принципы [2004: гл. XVI]. Он различает 2 бесконечности: бесконечность множественности и истинную бесконечность, превосходящую всякое число, а также все то, к чему приложима количественная характеристика [2008: 124]. Бесконечность множественности является лишь расширением и умножением индивидуального ко- 
нечного, и всегда снова сводима к нему же, реальная, напротив, не выводится из конечного, она не допускает никакого ограничения. Конечное, даже подвергнутое бесконечному продолжению, всегда есть ничто перед лицом истинного бесконечного [Генон 2012: 30]. Бесконечность невозможно постигнуть в ее тотальности на уровне человеческом, т. е. индивидуальном, но возможно рассматривать ее относительно какого-либо ее аспекта. Одним из аспектов бесконечности является аспект универсальной всевозможности. Всякая возможность проявления должна проявляться, и обратно, всякая возможность непроявления проявляться не должна. Возможности и проявления и непроявления существуют исходя из того, что область проявления ограничена тем, что она есть ансамбль относительных совозможностей, обусловленных миров и состояний, которые даже в своем бесчисленном множестве во всей своей целокупности не могли бы исчерпать универсальную возможность. Области проявления и непроявления являются коррелятивными и соотносительными друг с другом, а значит, они ограничивают друг друга, в то время как универсальная возможность, как аспект бесконечности не может быть ограничен ничем [Там же: 37]. По Р. Генону все возможное реально, хотя сам концепт «реальности» носит у него не вполне ясный, двойственный характер: если отрицать «реальность» непроявления, то тогда можно прийти к абсурдному заключению, что ансамбль и вся совокупность проявленного исчерпывают универсальную возможность. Лишь невозможное является чистым небытием, наглядным представлением невозможного является, например, квадратный круг - ансамбль проявления с противоречивыми характеристиками, невозможными с точки зрения их совмещения в одном феномене, при этом и круг, и квадрат реальны в отдельных проявлениях [Там же: 39]. Также и с пространством, временем и числом, ничто из выше перечисленного не может быть тотальным, если бы пространство было безграничным, то ни для какой непространственной возможности не было бы места. Пространство, как и время и число, есть лишь один из модусов проявления, соотносимых в одном ансамбле миров и состояний, как непротиворечивых совозможностей [Там же: 40].

Бытие - это принцип проявления, который по своей природе является непроявленным [Он же 2008: гл. I]. Бытие не совпадает с универсальной возможностью, вне бытия все возможности непроявления, вместе с возможностями проявления, находятся в потенциальном, непроявленном состоянии. Чтобы обозначить то, что находится за пределами бытия, вводится термин «не-бытие», этот термин не совпадает с «ничто» или в значении чистой негативации. Не-бытие больше, чем бытие, оно превосходит его, так как сам принцип бытия включен в него и из него проистекает; в небытие находится и актуальное непроявленное, и потенциальное проявленное. Раз бытие и не-бытие различаются, то ни то, ни другое не есть бесконечное, а значит, не совпадает с универсальной возможностью. Но ансамбль бытия и не-бытия бесконечен и тождественен универсальной возможности. Универсальная Возможность содержит в себе тотальность возможностей, а бытие и не-бытие - ее аспекты. Бытие содержит все проявленное, а не-бытие все непроявленное, включая само бытие как принцип проявления [Он же 2012: 42]. Состояние непроявления всегда постоянно и не обусловлено даже для возможностей проявления, находящихся в потенциальном состоянии. Ничто не теряется при переходе от актуально проявленного к потенциально проявляемому, т. е. происходит поистине «трансформация» в ее этимологическом смысле - переход по ту сторону формы. При этом «утрата» происходит только на уровне актуально проявленных форм, в состоянии непроявления же все находится вечно, независимо от всех частных форм обусловленности, характерных для проявления [Там же: 44]. Само различение бытия и не-бытия является произвольным, потому что может быть сделано только с точки зрения проявления. 
В качестве примера непроявляемой возможности можно привести пустоту, так как такая возможность постижима негативно, т. е. через исключение всех телесных или материальных атрибутов, всех конкретных качеств, всего, что относится к модусу проявления. Следовательно, считать, как делают это атомисты, что пустота и есть универсальная возможность, является нонсенсом, так как пустота сущностно принадлежит к области непроявления. Также пустота не есть не-бытие, а только одна из его возможностей, иных, нежели те, что содержатся в бытие. Любая из возможностей или аспектов не-бытия не может быть понята в модусах различения, поскольку такие модусы - прерогатива исключительно бытия. Поэтому всем возможностям небытия мы можем дать только совершенно негативное выражение [Генон 2012: 45]. Единое (бытие) есть только утвердительный метафизический ноль (не-бытие) [Там же: 46]. Не-бытие не является «ничто», оно являлось бы ему полной противоположностью, если бы «ничто» могло иметь свою противоположность (но это придало бы ему некую степень «позитивности», тогда как оно есть абсолютная негативность, т. е. невозможность). Поэтому «ничто» не противопоставляется бытию, оно противопоставлялось бы универсальной возможности, если бы оно могло каким-то образом реально войти в какую-либо оппозицию. Но поскольку реально только возможное, а «ничто» не возможно, то оно не может быть противопоставлено универсальной возможности [Там же: 47]. Состояния проявления - это бытие, рассматриваемое в его интегральности, оно соответствует различным степеням существования. Эти степени являются ничем иным, как разными модусами бесконечной множественности проявления. Разницу между бытием и универсальным существованием необходимо рассматривать, имея в виду, что бытие - это сам принцип проявления, а универсальное существование - это интегральное проявление ансамбля возможностей, имеющихся в бытии, это развертывание возможностей проявления в модусе обусловленности. Таким образом, бытие охватывает универсальное существование и превосходит его. Существование не тождественно бытию, так как последнее соответствует минимальной степени определенности и, следовательно, наивысшей степени универсальности. Само понятие существования (от латинского ex-stare) этимологически означает именно быть зависимым и обусловленным, следовательно, не иметь в самом себе собственного принципа или достаточного основания, т. е. существование случайно. Существование содержит в себе бесчисленность модусов и степеней проявления, которые все одинаково возможны, если реализованы в согласии с их собственными условиями. В все эти бесчисленные модусы коррелятивно предполагаются для некого существа и являются развертыванием его частной возможности [Он же 2008: гл. I; 2012: 50].

Среди состояний проявления имеются состояния иные, нежели человеческая индивидуальность, они могут быть индивидуальными существами (обладающими формой), тогда как другие являются не индивидуальными (не обладающими формой), природа их определена, как и место в иерархическом ансамбле бытия. Состояния непроявления сущностно неиндивидуальны, ибо необусловлены, они составляют то, что поистине универсально в каждом существе, то, посредством чего существо прикрепляется к своему трансцендентному принципу, без чего его существование было бы чистой иллюзией [Он же 2012: 52].

В не-бытии нет множественности и дифференциации, необусловленность не может подлежать определениям одного и множественности. Единичность и множественность возможны только в бытии, которое и является единым, оно коррелятивно содержит в себе множественность, которая начинается с первичного разделения на сущность и субстанцию [Там же: 54]. Бытие есть одно, универсальное существование является интегральным проявлением его возможности, оно, универ- 
сальное существование, «единственное» по своей сущности и внутренней природе. Ни «единое» бытия, ни «единственность» существования не исключают множество модусов проявления, как в общих и космических порядках, так и в порядке частных существований [Генон 2012: 56]. Понятие «единственность» является максимально приближенным значением арабского термина «вахдатул-вуджуд» - «сущее едино», что символизирует неразделимость единства и множественности как коррелятов друг друга. Множественность имеет собственный модус проявления, но его онтологический статус ничтожен, так как вытекает из единства. Стоит подчеркнуть разницу между «единством» и «единичностью», первое охватывает множественность как таковую, второе же есть его принцип [Он же 2004: гл. I; 2008: гл. II].

Различие между оформленной и неоформленной манифестацией в том, что индивидуальная манифестация всегда оформлена, ибо только наличие формы характеризует этот модус как индивидуальный. Индивидуальная манифестация делится на тонкую и грубую формы, тонкая форма является изначальной по отношению к грубой. Тонкая форма - это внетелесные модальности, грубая - это материальные формы. Если мы рассматриваем неоформленное проявление, то оно всегда сверхиндивидуальное. Неоформленная манифестация является изначальной в относительном смысле по отношению к оформленной, обе они являются аспектами одного принципа. Неоформленное проявленное хоть и является не индивидуальным порядком, но оно всегда, как и все проявленное, относительно и обусловлено [Он же 2004: гл. I].

Таким образом, если двигаться от максимально абстрактного к максимально конкретному, то метафизико-онтологическая схема Рене Генона будет иметь следующий вид: от бесконечности как высшего метафизического принципа переходим к ее аспекту универсальной всевозможности, от нее к не-бытию, от не-бытия к бытию, от бытия к универсальному существованию, от него к не-оформленному проявлению, от не-оформленного к оформленному, которое содержит в себе тонкую форму, которая первична по отношению к грубой.

Далее Рене Генон рассматривает эту схему, исходя из гносеологического подхода и терминологии адвайта-веданты, которая, по его мнению, является наиболее адекватной формой подлинного метафизического учения (в геноновском смысле термина «метафизика»). Так, аналогом бесконечности является термин «брахма» (санскр. brahma) - апофатический ноумен. С точки зрения гносеологии, он подлежит познанию через брахма-видья (санскр. brahma-vidya) - особый тип именно метафизического познания, основанный на предельной интуиции, это сверх-, или над-рассудочная форма познания, где нет никаких понятийных форм познания. Подлинный брахма не определим и за пределами любой двойственности, поэтому он nirguna - не имеющий качеств. Принцип, рассмотренный с онтологической точки зрения, т. е. с точки зрения универсальной проявленности, будет являться ишваpa (санскр. ishwara) - принципом бытия, наиболее общим из всех относительных категорий. С точки зрения гносеологии, он постигается с помощью ishwara-vidya - онтологического познания и вмещает в себя всю множественность форм бытия, сам являясь наиболее общим принципом бытия. Это конкретизированный принцип, значит, он не является уже более предельным метафизическим принципом, который вмещает в себя и бытие, и не-бытие, и является принципом онтологическим, поэтому он sarguna - имеющий качества [Там же]. Генон критикует современный декартовский подход в области познания - искусственное разделение познания и существования, он делает вывод о подлоге современной философии, которая заменяет само познание теорией познания и приводит ссылку на Аристотеля, который отождествляет существование и познание - «душа есть все, что она знает» [2013: 29]. 
Рене Генон подвергает критике западноевропейский универсализм и, соответственно, миф об особой миссии и самобытности древнегреческой цивилизации и о ее влиянии на все остальные соседствующие цивилизации - египетскую, финикийскую, персидскую, индийскую [2013: 30, 35]. Греческая цивилизация, по мнению Генона, напротив, несколько раз испытывала на себе благотворное воздействие идей именно восточной метафизики, что проявилось в метафизической части трудов Аристотеля и его силлогистике, идеях неоплатоников (таких, как метафизическая идея бесконечного). До появления этих идей греки обладали только понятием о неограниченном, а «конечное» и «идеальное» были для них синонимами [Там же: 46]. Р. Генон считает, что уже греческая мысль - основа современной западной цивилизации - несла в себе принципиальное отклонение от истины, так что эпоха Возрождения это отклонение лишь усилила, а Реформация довершила [Там же: $31,33]$. Главные обвинения, которые он предъявляет западноевропейской цивилизации, в том, что в ней произошло смешение метафизического и онтологического, подлинной бесконечности и бесконечности множественности, понимание интеллектуального было упрощено и интеллект был сведен только к рациональному [Там же: 36]. Р. Генон также утверждает, что западные языки лингвистически недостаточны и неточны в вопросах именно метафизических, что определило мышление людей Запада в целом и, в частности, их подход к метафизической проблематике. Он противопоставляет греческую склонность к натурализму метафизическому сосредоточению людей Востока [Там же: 38-39, 56]. По его мнению, именно смешение категорий метафизического и онтологического, лежащее в самом основании западноевропейской цивилизации, явилось причиной все более усиливающегося отклонения от истины и потери метафизического горизонта. Картезианский дуализм, антропоцентризм и индивидуализм, деонтологизация, позитивизм и утилитаризм современности вытекают именно из изначально неверной структурной топики основания западноевропейской цивилизации, определившей свое отклонение в качестве магистрального и универсального пути развития всего человечества.

Р. Генон в топике своего философствования конструирует, опираясь на структурный, компаративистский и лингвистический анализ инициатических традиций даосизма, адвайта веданты, суфийского ислама и других доступных ему традиций и источников - общую структурно-топологическую матрицу, создав тем самым некий вариант традиционного (или восточного) универсализма. Таким образом, интегральный традиционализм - это метафизико-онтологический конструкт, стоящий на аксиоматике премодерна, причем конструкт радикально инаковый всей традиции западной мысли. По мысли Р. Генона, он должен противостоять универсализму западноевропейского толка. От западной цивилизации он берет практически картезианский язык изложения, метод деконструкции инициатических традиций, а от традиционного Востока перенимает метафизико-онтологическую матрицу и аксиоматику премодерна.

\section{Аитература}

Генон Р. Человек и его осуществление согласно Веданте. Восточная метафизика / Р. Генон; пер. с фр. Н. Тирос. - М.: Беловодье, 2004.

Генон Р. Символизм креста / Р. Генон. - М.: Беловодье, 2008. - 224 с.

Генон Р. Множественные состояния бытия (сборник) / Р. Генон; пер. с фр. Т. Любимовой. - М.: Беловодье, 2012.

Генон Р. Общее введение в изучение индусских учений / Р. Генон; пер. с фр. М. Маковчика. - М.: Беловодье, 2013. - 321 с.

Дугин А. Философия традиционализма / А. Дугин. - М.: Арктогея-Центр, 2002. - 624 с. 
Kapneu B. Онтология и метафизика у Рене Генона / В. Карпец [Электронный ресурс]. - Режим доступа: https://youtu.be/QwrLos0uWuI; https://youtube/KbHX_KwH880 (дата обращения: 16.12.2018).

Стефанов Ю. Рене Генон и философия традиционализма / Ю. Стефанов // Вопросы философии. - 1991. - № 4. - С. 31-42.

Стефанов Ю. Рыцарь традиции / Ю. Стефанов // Литературное обозрение. - 1994. № 4. - C. 48-52.

Сэджвик M. Наперекор современному миру: традиционализм и тайная интеллектуальная история XX века / М. Сэджвик; пер. с англ. М. Маршака, А. Лазарева. - М.: НЛО, 2014. $-536 \mathrm{c}$.

Alleau Rene. René Guénon et l'Actualite de la Pensee Traditionnelle: Actes du Colloque International de Cerisy-La-Salle; 13-20 Julliet 1973 / Rene Alleau, M. Scriabine. - Paris: Dervy Livres, 1981. $-333 \mathrm{p}$.

Vallin Georges. La perspective métaphysique / Georges Vallin. - Paris: Presses universitaires de France, 1959. - 253 p.

Kennedy W. H. Occult History (Collected Writings 1994-2008) [Elektronnyj resurs]. Rezhim dostupa: https://ru.scribd.com/doc/155579092/Occult-History-William-H-Kennedy (дата обращения: 16.12.2018).

\section{Reference}

Genon R. Chelovek i ego osushchestvlenie soglasno Vedante. Vostochnaya metafizika / R. Genon; per. s fr. N. Tiros. - M.: Belovod'e, 2004.

Genon R. Simvolizm kresta / R. Genon. - M.: Belovod'e, 2008. - 224 s.

Genon R. Mnozhestvennye sostoyaniya bytiya (sbornik) / R. Genon; per. s fr. T. Lyubimovoj. - M.: Belovod'e, 2012.

Genon R. Obshchee vvedenie v izuchenie indusskih uchenij / R. Genon; per. s fr. M. Makovchika. - M.: Belovod'e, 2013. - 321 s.

Dugin A. Filosofiya tradicionalizma / A. Dugin. - M.: Arktogeya-Centr, 2002. - 624 s.

Karpec $V$. Ontologiya i metafizika u Rene Genona / V. Karpec [Elektronnyj resurs]. - Rezhim dostupa: https://youtube/QwrLos0uWuI; https://youtu.be/KbHX_KwH880 (data obrashcheniya: 16.12.2018).

Stefanov Yu. Rene Genon i filosofiya tradicionalizma / Yu. Stefanov // Voprosy filosofii. 1991. - № 4. - S. 31-42.

Stefanov Yu. Rycar' tradicii / Yu. Stefanov // Literaturnoe obozrenie. - 1994. - № 4. S. 48-52.

Sedzhvik M. Naperekor sovremennomu miru: tradicionalizm i tajnaya intellektual'naya istoriya XX veka / M. Sedzhvik; per. s angl. M. Marshaka, A. Lazareva. - M.: NLO, 2014. - 536 s.

Alleau Rene. René Guénon et l'Actualite de la Pensee Traditionnelle: Actes du Colloque International de Cerisy-La-Salle; 13-20 Julliet 1973 / Rene Alleau, Scriabine M. - Paris: Dervy Livres, 1981. $-333 \mathrm{p}$.

Vallin Georges. La perspective métaphysique / Georges Vallin. - Paris: Presses universitaires de France, 1959. - 253 p.

Kennedy W. H. Occult History (Collected Writings 1994-2008) [Elektronnyj resurs]. Rezhim dostupa: https://ru.scribd.com/doc/155579092/Occult-History-William-H-Kennedy (data obrashcheniya: 16.12.2018). 